\title{
Adrenal inhibition following a single dose of etomidate in intubated traumatic brain injury victims
}

\author{
Patrick Archambault, MD, MSc**; Clermont E. Dionne, $\mathrm{PhD}^{\S}$; Gilles Lortie, $\mathrm{MD}, \mathrm{PhD}^{\ddagger \|}$; \\ François LeBlanc, MD*; Anik Rioux, MSc\#; Geneviève Larouche, MSc**
}

\section{ABSTRACT}

Background: Etomidate is frequently used to intubate traumatic brain injury (TBI) victims, even though it has been linked to adrenal insufficiency (Al) in some populations. Few studies have explored the risk of prolonged etomidateinduced $\mathrm{Al}$ among TBI victims.

Objective: To determine the risk and the length of $\mathrm{Al}$ induced by etomidate in patients intubated for moderate and severe TBI.

Methods: Participants in this observational study were moderate to severe intubated TBI victims aged $\geq 16$ years. The anesthetic used (etomidate versus others) was determined solely by the treating emergency physician. Adrenocorticotropic hormone (ACTH) stimulation tests $(250 \mu \mathrm{g})$ were performed 24,48 , and 168 hours after intubation. Al was defined as an increase in serum cortisol 1 hour post-ACTH test (delta cortisol) of less than $248.4 \mathrm{nmol} / \mathrm{L}$.

Results: Forty subjects (participation 42.6\%) underwent ACTH testing. Fifteen received etomidate, and 25 received another anesthetic. There were no statistically significant differences between groups as to the cumulative incidence of $\mathrm{Al}$ at any measurement time. However, at 24 hours, exploratory post hoc analyses showed a significant decrease in delta cortisol (adjusted means: etomidate group: $305.1 \mathrm{nmol} / \mathrm{L}, 95 \% \mathrm{Cl}$ 214.7-384.8 versus other anesthetics: $500.5 \mathrm{nmol} / \mathrm{L}, 95 \% \mathrm{Cl}$ 441.8-565.7). This decrease was not present at 48 and 168 hours.

Conclusion: In TBI victims, although a single dose of etomidate does not increase the cumulative incidence of $\mathrm{Al}$ as defined, it seems to decrease the adrenal response to an
ACTH test for 24 hours. The clinical impacts of this finding remain to be determined.

\section{RÉSUMÉ}

Contexte: L'étomidate est souvent utilisé dans l'intubation des personnes ayant subi une lésion cérébrale traumatique (LCT), malgré le fait que le produit soit lié à une insuffisance surrénalienne (IS) dans certains groupes de patients. Peu d'études ont porté sur le risque d'IS prolongée, causée par l'étomidate, chez les patients ayant subi une LCT.

Objectif: L'étude visait à déterminer le risque d'IS causée par l'étomidate, et sa durée, chez des patients intubés après avoir subi une LCT modérée ou grave.

Méthodes: Les participants à cette étude d'observation étaient des personnes âgées de 16 ans et plus, intubées après avoir subi une LCT modérée ou grave. Le choix de I'anesthésique (étomidate ou autres produits) ne relevait que de I'urgentologue traitant. Des épreuves de stimulation par la corticotrophine (ACTH; $250 \mu \mathrm{g})$ ont été effectuées 24 , 48, et 168 heures après I'intubation. L'IS a été définie comme une augmentation du cortisol sérique, inférieure à $248.4 \mathrm{nmol} / \mathrm{L}$, 1 heure après l'administration d'ACTH (delta cortisol).

Résultats: Quarante sujets (participation 42.6\%) ont été soumis à des épreuves à I'ACTH. Quinze avaient reçu de I'étomidate et 25 un autre anesthésique. II n'y avait pas de différence statistiquement significative entre les groupes en ce qui concerne I'incidence cumulée de I'IS, à n'importe quel point de mesure dans le temps. Toutefois, les analyses exploratoires, au bout de 24 heures, ont révélé une diminution importante du delta cortisol (moyennes ajustées:

From the *Departments of Emergency Medicine and Anesthesiology, Centre de santé et de services sociaux Alphonse-Desjardins (Centre Hospitalier Affilié Universitaire de Lévis), Lévis, QC; †Traumatologie - urgence - soins intensifs, Centre de recherche FRSQ du CHA universitaire de Québec, Québec City, QC; ‡Département de médecine familiale et de médecine d'urgence, Université Laval, Québec City, QC; §URESP, Centre de recherche FRSO du CHA universitaire de Québec, Québec City, QC; \#Department of Emergency Medicine, Centre de santé et de services sociaux AlphonseDesjardins (Centre Hospitalier Affilié Universitaire Hôtel-Dieu de Lévis), Lévis, QC; - Department of Medicine and Division of Critical Care, CHA universitaire de Québec (Hôpital de I'Enfant-Jésus), Québec City, QC; \#Department of Pharmacy, Hôpital de Gatineau, Gatineau, QC; **Department of Pharmacy, Centre Hospitalier Universitaire de Québec, Québec City, QC.

Correspondence to: Dr. Patrick Archambault, CSSS Alphonse-Desjardins (CHAU de Lévis), 143, rue Wolfe, Lévis, Quebec, QC G6V 3Z1; patrick.m. archambault@gmail.com.

This article has been peer reviewed. 
étomidate: $305.1 \mathrm{nmol} / \mathrm{L}$, IC à 95\% 214.7-384.8; autres anesthésiques: $500.5 \mathrm{nmol} / \mathrm{L}$, IC à 95\% 441.8-565.7), mais cette diminution avait disparu au bout de 48 et 168 heures.

Conclusion: Bien que l'administration d'une seule dose d'étomidate chez les personnes ayant subi une LCT n'augmente pas I'incidence cumulée de I'IS, telle qu'elle a été définie ici, elle semble toutefois diminuer la réaction surrénalienne à l'épreuve de stimulation par l'ACTH pendant 24 heures. On ne connaît cependant pas la portée clinique de cette constatation.

Keywords: adrenal insufficiency, etomidate, traumatic brain injury
Etomidate is one of the most frequently used anesthetics for intubating head trauma patients. ${ }^{1-3}$ The favourable cardiovascular and neuroprotective effects of etomidate make it an ideal agent for these patients., ${ }^{4,5}$ Although etomidate is safe in elective surgical patients, ${ }^{6-10}$ in critically ill patients, studies have shown adrenal insufficiency (AI) lasting 48 hours after a single bolus. ${ }^{11-13}$ Authors have therefore suggested that etomidate be avoided for critically ill patients, especially those in septic shock. ${ }^{14-17}$ In trauma patients, a randomized, controlled trial (RCT) comparing etomidate to fentanyl showed that etomidate increased the risk of AI measured 6 hours after administration. Etomidate was also related to more ventilator days and longer intensive care unit (ICU) lengths of stay. ${ }^{18}$ An RCT that enrolled 469 patients showed that etomidate did not increase 28-day mortality compared to ketamine ( $81 \%$ versus $72 \%, p=0.2$ ); however, it increased the risk of AI ( $86 \%$ versus $56 \%, p<$ 0.0001 ) measured 7 hours after administration. In a subgroup of 104 trauma patients, including 78 traumatic brain injury (TBI) victims, this RCT found no differences in outcomes between the two agents. ${ }^{19}$ A systematic review on the impact of etomidate on all patient populations could not conclude definitively about the possible harm or benefit of etomidate on mortality, ventilator duration, ICU length of stay, and adrenal suppression beyond 12 hours because of limited data. ${ }^{20}$ Thus, more research is needed on this topic.

\section{IMPORTANCE OF THE QUESTION}

Every year, about 1.5 million patients die from TBI worldwide. ${ }^{21,22}$ Given that TBI victims are known to be at risk for AI from injury to the pituitary gland ${ }^{23-25}$ and from other causes, ${ }^{26,27}$ the additional AI that could result from using etomidate might increase TBI mortality and morbidity. Given that high-dose corticosteroids have been shown to increase TBI mortality, ${ }^{28,29}$ corticosteroids are avoided in this population. This decrease in the use of corticosteroids offers an opportunity to better determine the length of etomidate-induced $\mathrm{AI}$ and to assess the deleterious effects of etomidate-induced $\mathrm{AI}$ in TBI victims.

\section{OBJECTIVE OF INVESTIGATION}

We sought to determine the risk and length of AI after a single bolus dose of etomidate to intubate TBI victims in an emergency department (ED).

\section{METHODS}

\section{Study design and setting}

Subjects of this observational study were recruited at a level 1 trauma centre with the approval of the Institutional Review Board. Two groups were constituted: one group of patients who had received etomidate and another group composed of patients who had received any other anesthetic. Exposure to etomidate was not randomized but was determined by the treating emergency physician. We performed three high-dose $(250 \mu \mathrm{g})$ adrenocorticotropic hormone (ACTH) stimulation tests on each subject 24, 48, and 168 hours after administration of etomidate and compared the cumulative incidence and length of $\mathrm{AI}$ of the two groups.

\section{Selection of participants}

All trauma victims seen in the ED during the recruitment period (August 2003 to October 2004) aged $\geq 16$ years were considered for inclusion. Patients transferred from other hospitals within 24 hours after intubation were also eligible. Inclusion criteria consisted of intubated moderate and severe TBI victims with or without other organ injuries, a Glasgow Coma Scale (GCS) score $\leq 12$, and evidence of brain injury on a computed tomographic (CT) scan as determined by a radiologist. Patients were excluded if they were allergic to cosyntropin (ACTH), were known to have pre-existing AI, had received systemic corticosteroids in the previous 6 months, had received corticosteroids during the first 24 hours of the study, had 
undergone pituitary surgery, developed cerebral death in the first 24 hours of the study, were septic at the moment of intubation, were taking ketoconazole, were pregnant, or were seropositive for human immunodeficiency virus (HIV). Screening for eligible patients was performed daily in the ED and ICU. We contacted family members to assess exclusion criteria and seek consent in the first 24 hours after intubation. Patients were excluded if consent could not be obtained in the first 24 hours.

\section{Interventions}

As this was an observational study, etomidate and other anesthetics were administered according to drug availability and physicians' preferences. Thus, physicians were not blinded to the anesthetic used.

Patients underwent ACTH stimulation tests 24, 48, and 168 hours after intubation. Serum cortisol levels were determined at baseline and 30 and 60 minutes after administering ACTH in any available intravenous line. Blood samples were sent immediately to the laboratory, where they were centrifuged and frozen.

\section{Methods of measurement}

Samples were analyzed in batches using the same AxSym immunoassay system from Abbott (Abbott Park) so as to decrease interassay variability. The coefficient of variability was 10 to $15 \%$ for $75 \mathrm{nmol} / \mathrm{L}, 5 \%$ for $450 \mathrm{nmol} / \mathrm{L}$, and $6 \%$ for $850 \mathrm{nmol} / \mathrm{L} .{ }^{30}$ When levels of cortisol were over $1,656 \mathrm{nmol} / \mathrm{L}$, a dilution process was performed, introducing negligible imprecision.

The treating physician was not given the assay results. When she or he requested immediate results, additional assays were performed with the Beckman Coulter Access Immunoassay System (Beckman Coulter, Inc., Brea, CA), the only system in our hospital that can produce immediate results 24 hours per day.

\section{Data collection and processing}

The results for cortisol assays were collected by a biochemist who was blinded to the anesthetic used. For all patients screened, we collected baseline data about age, gender, GCS score, anesthetic used, and reason for exclusion (if applicable). Other baseline characteristics were collected retrospectively from the Quebec Trauma Registry or extracted from the medical charts using a structured data collection form. Follow-up ended at hospital discharge and was completed for every subject enrolled.

\section{Outcome measures}

The primary outcome measure was the cumulative incidence of $\mathrm{AI}$ at 24, 48, and 168 hours. As per Annane and colleagues' criterion, ${ }^{31}$ we defined AI as a delta cortisol of less than $248.4 \mathrm{nmol} / \mathrm{L}$. Although controversial, ${ }^{32}$ this definition has been associated with increased mortality in septic shock patients. ${ }^{33}$ Delta cortisol was defined as the difference between the maximum increase in cortisol at 30 or 60 minutes after the ACTH stimulation test and the baseline cortisol level. Secondary outcomes were mortality and cumulative incidence of patients treated for adrenal insufficiency at 7 days.

Given that this study was observational, potential confounding variables had to be measured to adjust estimates of the strength of the associations. A priori, we selected three variables in this regard: age, gender, and the Injury Severity Score (ISS). In light of research published after our study began, we also considered other potentially confounding variables (Appendix 1).

\section{Statistical analysis}

The distribution of variables was first verified, and missing or outlying data were checked to control quality. We compared baseline demographic variables using the chi-square test, Fisher exact test, Student $t$ test, or Mann-Whitney test. Then we analyzed the crude association between exposure to etomidate and the cumulative incidence of $\mathrm{AI}$ at 24, 48, and 168 hours in bivariate analyses using the Fisher exact test. Mortality and cumulative incidence of patients treated for AI were also analyzed using the Fisher exact test. In an exploratory post hoc analysis, we compared delta cortisol in bivariate analyses using the Mann-Whitney test to assess the effect of etomidate on adrenal reserve at 24, 48, and 168 hours. We also performed multiple logistic regression analyses (planned a priori for cumulative incidence of $\mathrm{AI}$ ) and analysis of covariance (performed post hoc for delta cortisol) to produce results adjusted for actual confounders. Potential confounding variables that changed the regression coefficient of exposure to etomidate by $>10 \%$ were kept in the final models. To test the robustness of the final models, we analyzed the outlying residuals. The level of significance retained for all analyses was 0.05 . 
Sensitivity analyses were performed to estimate the impact of a potential selection bias on outcomes (Appendix 2). Data were analyzed using the $S A S$ version 9.1 statistical program (SAS Institute, Cary, NC).

\section{RESULTS}

\section{Characteristics of the study subjects}

Figure 1 shows the flow of patients in the study. Among the 185 patients considered, 94 were eligible to participate. Nineteen were excluded because of corticosteroid use (see Figure 1). The 54 missed patients were less severely injured than participants (Appendix 3). Overall, 40 patients underwent ACTH stimulation tests (participation 42.6\%), with 15 having received etomidate and 25 having received another induction agent. Table 1 presents the characteristics of these subjects. The only statistically significant differences between both groups were that patients who received etomidate were more likely to have been intubated at the level I trauma centre (without transfer) $(p<0.0001)$ and had shorter transfer times $(p=0.002)$ than those who had received another agent. Without reaching statistical significance, there was a trend for patients who received etomidate to be younger $(p=0.11)$, to have higher ISSs $(p=0.23)$, and to have a lower mean arterial pressure $(p=0.48)$.

\section{Main results}

Table 2 presents the results of bivariate analyses conducted for the primary and secondary outcomes. The results do not show that etomidate significantly increases the cumulative incidence of AI defined as a delta cortisol less than $248.4 \mathrm{nmol} / \mathrm{L}$ at any measurement time. Over the 7 days, the cumulative incidence was 7 of $15(26.7 \%)$ in the etomidate group and 4 of 25 $(16 \%)$ in the other anesthetic group.

At 24 hours, the crude odds ratio of AI was 1.8 (95\% CI 0.3-10.5); it was 4.6 (95\% CI 0.3-67.5) after adjustments. In both cases, the confidence intervals were very large and indicated no effect of etomidate on the risk of AI at 24 hours defined as a delta cortisol less than $248.4 \mathrm{nmol} / \mathrm{L}$. However, our exploratory post hoc analyses found that etomidate negatively impacts delta cortisol at 24 hours. As shown in Figure 2 and Table 3, the etomidate group had significantly lower crude delta cortisol results at 24 hours than the other group. This difference remained significant after adjustment for confounders (see Table 3) and when extreme values were excluded from the regression model. At 48 and 168 hours, this effect was not present.

Table 4 (etomidate group) and Table 5 (other anesthetic group) present crude results for baseline cortisol and delta cortisol for each patient included in this study. The reasons for censoring are described as well. Three deaths occurred in the etomidate group during the first 7 days ( 3 of $15 ; 20 \%$ ) compared to one death in the other group ( 1 of $25 ; 4 \%$ ). This difference in mortality was not statistically significant (see Table 2). One of the deceased patients exposed to etomidate had proven AI (see Table 4, patient 8). The only death in the other group was not related to AI. None of the deceased patients had received hydrocortisone. Hydrocortisone was given to three patients (20\%) exposed to etomidate and to two patients (8\%) in the other group (see Table 2). Of the three etomidate recipients treated with hydrocortisone, one had proven AI as per ACTH testing (see Table 4, patient 14). This patient also had possible hypopituitarism with diabetes insipidus. Another etomidate recipient treated with hydrocortisone had a normal delta cortisol assay measurement (250.4 nmol/L) as per the AxSym immunoassay system but received hydrocortisone because clinicians suspected AI and performed a simultaneous assay with the Access immunoassay system, which found an abnormal delta cortisol (213 nmol/L) (see Table 4, patient 10). No subjects in the other group with biochemically proven AI received hydrocortisone. Both hydrocortisone recipients in the other anesthetic group were considered to have hypopituitarism as per pituitary hormonal assays (Table 5, patients 10 and 13).

\section{DISCUSSION}

\section{Comparison with previous literature}

Our study did not find a statistically significant difference in the cumulative incidence of $\mathrm{AI}$ at 24, 48, or 168 hours. In comparison with Vinclair and colleagues, who showed that etomidate-induced AI lasted up to 48 hours in a group of critically ill patients ( $\mathrm{n}=40$, including 18 trauma victims), ${ }^{13}$ we found a lower risk of $\mathrm{AI}$ at 24 hours (20\%) and 48 hours (9\%) than they did (49\% and 22\%, respectively). This difference might be due to the inclusion of patients with spontaneous subarachnoid hemorrhage who might 


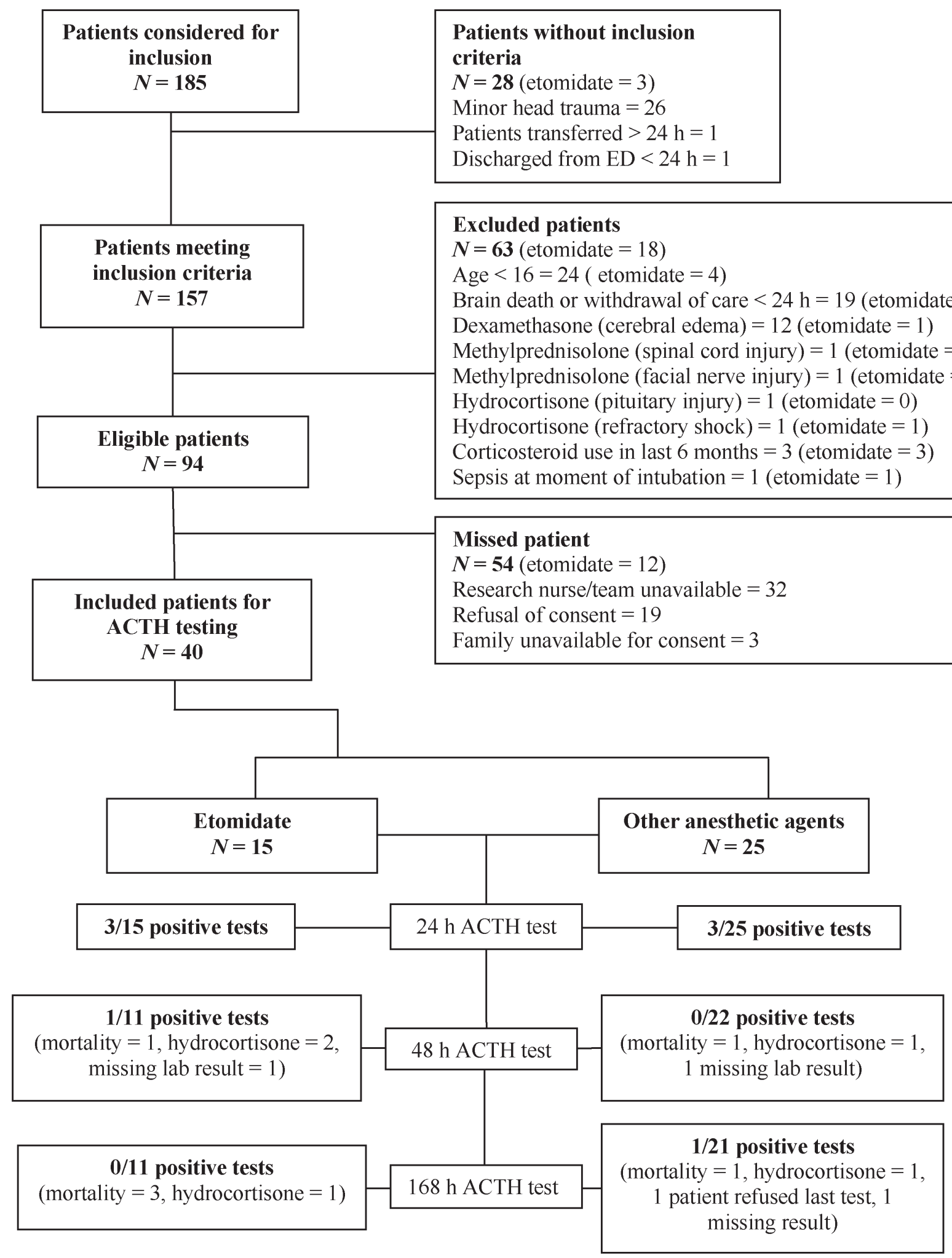

Figure 1. Flow of subjects through the study. ACTH = adrenocorticotropic hormone; ED = emergency department.

have a higher risk of AI. ${ }^{34}$ Our results are consistent with the findings of Hildreth and colleagues, where the etomidate group presented a blunted response to
ACTH 6 hours postintubation (delta cortisol $=116 \pm$ $135 \mathrm{nmol} / \mathrm{L})$ compared to the fentanyl-midazolam group $($ delta cortisol $=309 \pm 168 \mathrm{nmol} / \mathrm{L}) \cdot{ }^{18}$ 


\begin{tabular}{|c|c|c|}
\hline & Etomidate $(n=15)$ & Other anesthetics $(n=25)$ \\
\hline Mean age, yr (SD) & $35(12)$ & $45(19)$ \\
\hline Male sex, $n(\%)$ & $11(73)$ & $18(72)$ \\
\hline Mean arterial pressure, $\mathrm{mm} \mathrm{Hg}$ (SD) & $84(20)$ & $90(26)\{1\}^{*}$ \\
\hline Mean GCS score (SD) & 7 (3) & $7(3)$ \\
\hline \multicolumn{3}{|l|}{ GCS score ranges, $n(\%)$} \\
\hline $14-15$ & $1(7)$ & $1(4)$ \\
\hline $9-13$ & $4(27)$ & $5(20)$ \\
\hline $3-8$ & $10(66)$ & $19(76)$ \\
\hline Subjects transferred, (n (\%) & $4(27)$ & $22(88)$ \\
\hline Subjects who underwent surgery in first $24 \mathrm{~h}, n(\%)$ & $6(40)$ & $8(32)$ \\
\hline \multicolumn{3}{|l|}{ Mechanism of injury, $n(\%)$} \\
\hline Motor vehicle & $11(73)$ & $16(64)$ \\
\hline Fall & $4(27)$ & $7(28)$ \\
\hline Isolated blunt head injury & 0 & $2(8)$ \\
\hline Alcohol detected in blood test, $n(\%)$ & $4(27)$ & $5(21)$ \\
\hline Illicit drug detected in urine test, $n(\%)$ & $1(7)$ & $2(8)$ \\
\hline Mean ISS score (SD) & $35(12)$ & $31(9)$ \\
\hline \multicolumn{3}{|l|}{ ISS score ranges, $n(\%)$} \\
\hline $0-24$ & $2(13)$ & $5(20)$ \\
\hline $25-49$ & $10(67)$ & $20(80)$ \\
\hline $50-75$ & $3(20)$ & 0 \\
\hline APACHE II score (SD) & $20(7)$ & $19(5)$ \\
\hline $\begin{array}{l}\text { Median units of packed red blood cells administered (IQR } \\
25-75 \%)\end{array}$ & $0(0-2)$ & $0(0-0)$ \\
\hline Vasopressors used, $n(\%)$ & $1(7)$ & $3(13)$ \\
\hline Median transfer time, h (IQR 25-75\%) & $0.9(0.6-7.4)$ & $5.3(3.2-7.3)\{1\}^{*}$ \\
\hline $\begin{array}{l}\text { Median total fluid volume in the emergency department, } \mathrm{mL} \\
\text { (IQR } 25-75 \% \text { ) }\end{array}$ & $1,640(820-3,350)$ & $2000(900-3,000)$ \\
\hline
\end{tabular}

Other studies have reported varying estimates of the risk of AI following TBI ranging between $15 \%{ }^{24}$ and $53 \%,{ }^{26}$ depending on the definition of AI used, ${ }^{26}$ the population studied, ${ }^{35}$ the exposure to etomidate, ${ }^{35}$ and the time at which the ACTH test was performed, ${ }^{35}$ making comparisons difficult. For example, using the same definition, Bernard and colleagues found a higher risk of $\mathrm{AI}(25 \%)$ in TBI victims not exposed to etomidate compared to our study (12\%). ${ }^{36}$ However, all patients in this study were hemodynamically unstable, increasing their risk of AI. Thus, we agree with Bernard and colleagues, who called for more standardization in the definition of $\mathrm{AI}$ after TBI. ${ }^{36} \mathrm{We}$ would add that the time elapsed after TBI is also important in reporting the risk of AI.

In contrast to our results, etomidate seemed to cause less $\mathrm{AI}$ in TBI victims than in patients with severe hemorrhagic shock (47\%), ${ }^{37}$ those with septic shock $(94 \%),{ }^{31}$ and critically ill surgical patients (88\%). ${ }^{11}$

\section{Strengths of the study}

This is the first study to perform serial ACTH stimulation tests at predetermined time points beyond the first 12 hours and in the first 7 days after TBI to formally measure the cumulative incidence of $\mathrm{AI}$ in moderate and severe TBI patients exposed to etomidate and in those not exposed to etomidate. Our results also add to the limited data available on the use of etomidate in TBI and trauma victims (Hildreth and colleagues, $n=30^{18}$; Jabre and colleagues, $n=78$ [subgroup of TBI victims] ${ }^{19}$; Vinclair and colleagues, $n=18$ [subgroup of trauma patients] Price and colleagues, $n=22^{35}$; Cohan and colleagues, $n=$ $80^{26}$; and Hoen and colleagues, $n=34^{37}$ ).

\section{Study limitations}

Our study was exposed to a potential selection bias because of the low participation rate. Thus, we 
Table 2. Crude comparison of exposure groups for the primary and secondary outcomes

\begin{tabular}{|c|c|c|c|}
\hline & $\begin{array}{l}\text { Etomidate } \\
(n=15)\end{array}$ & $\begin{array}{l}\text { Other induction } \\
\text { agents }(n=25)\end{array}$ & $p$ value ${ }^{*}$ \\
\hline Cumulative incidence of $\mathrm{Al}$ at $24 \mathrm{~h}(\%)$ & $3(20.0)$ & $3(12.0)$ & 0.65 \\
\hline Cumulative incidence of $\mathrm{Al}$ at $48 \mathrm{~h}(\%)$ & $4(26.7)^{\dagger}$ & $3(12.0)^{\ddagger}$ & 0.39 \\
\hline Cumulative incidence of $\mathrm{Al}$ at $168 \mathrm{~h}(\%)$ & $4(26.7)^{\S}$ & $4(16.0)^{\|}$ & 0.44 \\
\hline Positive ACTH test at $24 \mathrm{~h}(\%)$ & $3(20.0)$ & $3(12.0)$ & 0.65 \\
\hline Positive ACTH test at $48 \mathrm{~h}(\%)$ & $1(9.1)^{\dagger}$ & $0^{\ddagger}$ & 0.33 \\
\hline Positive ACTH test at $168 \mathrm{~h}(\%)$ & $0^{\S}$ & $1(4.8)^{\|}$ & 0.54 \\
\hline Patients treated for suspected Al during the first 7 days (\%) & $3(20.0)$ & $2(8.0)$ & 0.34 \\
\hline Mortality at 168 days & $3(20.0)$ & $1(4.0)$ & 0.14 \\
\hline \multicolumn{4}{|c|}{ 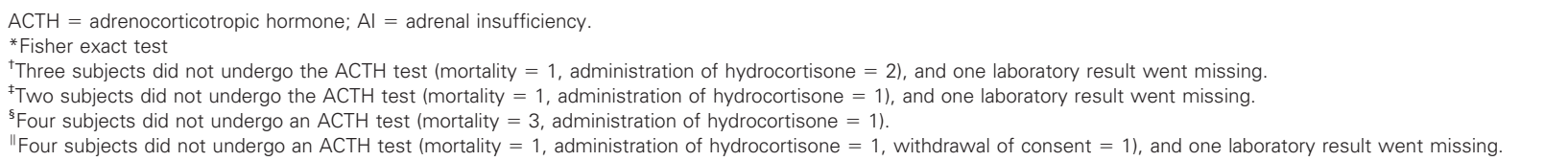 } \\
\hline
\end{tabular}

conducted sensitivity analyses (Appendix 2) to estimate the impact of eligible patients who did not participate $(n=54)$ on our results. Although these analyses showed that imputing normal results to these patients favoured the null hypothesis, the direction of the negative effect of etomidate on adrenal responsiveness to ACTH stimulation did not change. Hence, we think it is safer to place greater weight on the results from the worst-case scenario so as to expose all possible harm of continued use of etomidate.

Our results can be generalized to all adult patients with moderate and severe TBI; however, this study should be reproduced in the pediatric population because our study only included four patients aged between 16 and 18 years.

Clinicians were not blinded to the anesthetic used, and it is possible that they perceived subjects exposed to etomidate as being at a higher risk for $\mathrm{AI}$ and thus administered more hydrocortisone to members of this group, exposing the study to a possible Hawthorne effect. ${ }^{38}$ Among the 40 subjects tested, 5 were clinically diagnosed with $\mathrm{AI}$ requiring hydrocortisone and 3 of them had received etomidate. This potential effect prohibits any conclusion about the association between etomidate exposure and the need for hydrocortisone, but it does not influence our results for the laboratory diagnosis of AI.

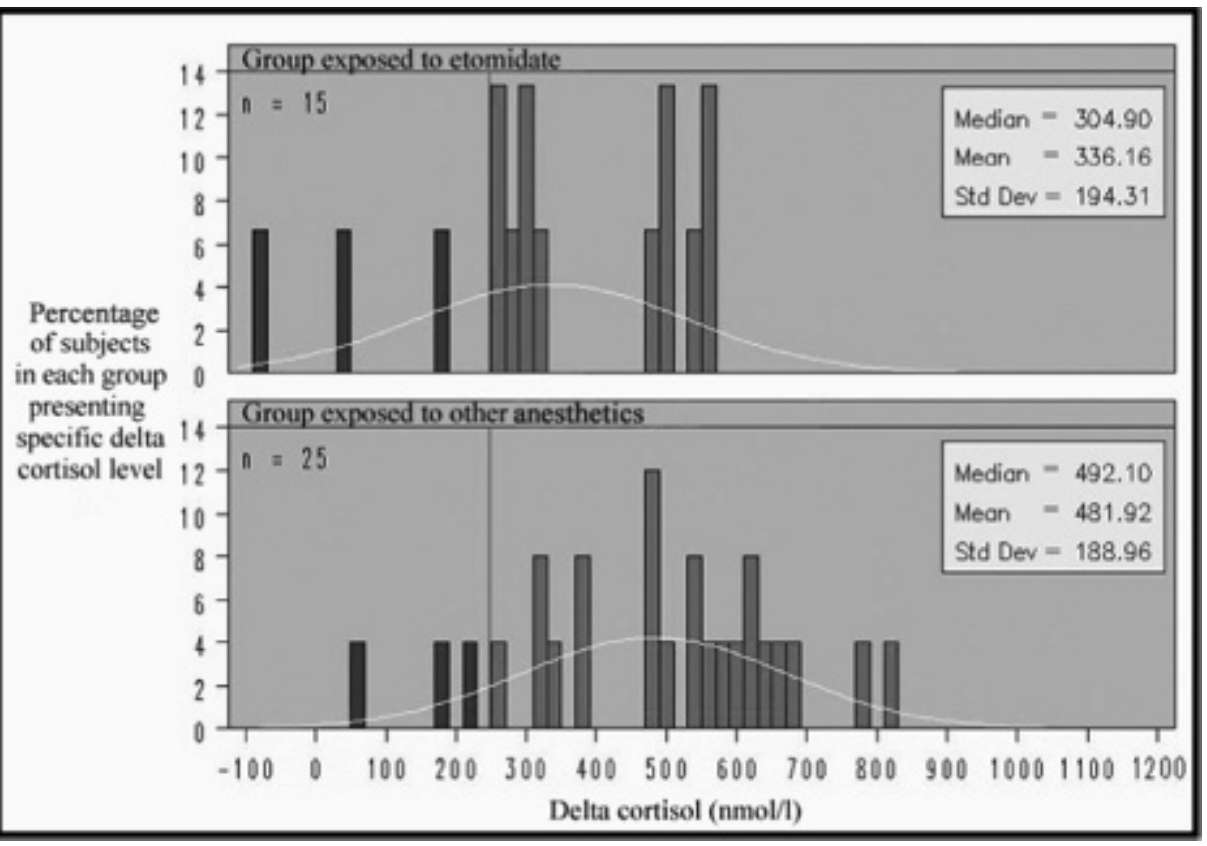

Figure 2. Distribution plots for crude delta cortisol measured at 24 hours by exposure group. The white line represents the normal distribution curve. The thin black vertical line represents the delta cortisol cutoff criteria for adrenal insufficiency ( $<248.4 \mathrm{nmol} / \mathrm{L})$. 


\begin{tabular}{|c|c|c|c|}
\hline & $\begin{array}{c}\text { Etomidate, } \\
\mathrm{nmol} / \mathrm{L}(95 \% \mathrm{Cl})\end{array}$ & $\begin{array}{c}\text { Other agents, } \\
\mathrm{nmol} / \mathrm{L}(95 \% \mathrm{Cl})\end{array}$ & $p$ value $^{\dagger}$ \\
\hline Cortisol level* before ACTH test at $24 \mathrm{~h}$ & $525.8(326.8-724.8)$ & $574.8(423.7-725.9)$ & 0.72 \\
\hline Delta cortisol* after the ACTH test at $24 \mathrm{~h}$ & $336.2(228.6-443.8)$ & 481.9 (403.9-559.9) & 0.03 \\
\hline Adjusted $^{\ddagger}$ delta cortisol* at $24 \mathrm{~h}$ & $\begin{array}{c}305.1(197.8-412.4) \\
n=15\end{array}$ & $\begin{array}{c}500.5(421.9-579.2) \\
n=25\end{array}$ & 0.02 \\
\hline Cortisol level* before ACTH test at $48 \mathrm{~h}$ & $\begin{array}{c}396.3(202.5-590.1) \\
n=11\end{array}$ & $\begin{array}{c}397.5(411.8-728.8) \\
n=22\end{array}$ & 0.98 \\
\hline Delta cortisol* at $48 \mathrm{~h}$ & $\begin{array}{c}569.9(447.1-692.7) \\
n=11\end{array}$ & $\begin{array}{c}634.8(548.0-721.6) \\
n=22\end{array}$ & 0.43 \\
\hline Adjusted $^{\ddagger}$ delta cortisol* at $48 \mathrm{~h}$ & $\begin{array}{c}570.3(411.8-728.8) \\
n=11\end{array}$ & $\begin{array}{c}634.8(532.2-737.4) \\
n=22\end{array}$ & 0.57 \\
\hline Cortisol level* before ACTH test at $168 \mathrm{~h}$ & $\begin{array}{c}397.5(312.5-482.6) \\
n=11\end{array}$ & $\begin{array}{c}436.4(339.4-533.3) \\
n=22^{\S}\end{array}$ & 0.41 \\
\hline Delta cortisol* at $168 \mathrm{~h}$ & $\begin{array}{c}627.9(496.2-759.6) \\
n=11\end{array}$ & $\begin{array}{c}582.4(487.1-677.7) \\
n=21^{5}\end{array}$ & 0.74 \\
\hline Adjusted $^{\ddagger}$ delta cortisol* at $168 \mathrm{~h}$ & $\begin{array}{c}662.8(484.6-841.1) \\
n=11\end{array}$ & $\begin{array}{c}561.0(444.4-677.6) \\
n=21^{\S}\end{array}$ & 0.48 \\
\hline \multicolumn{4}{|c|}{$\begin{array}{l}\text { ACTH = adrenocorticotropic hormone. } \\
{ }^{*} \text { Cortisol and delta cortisol levels are presented as means. } \\
\text { "Mann-Whitney test with normal approximation. } \\
\text { FAdjusted for age, gender, Injury Severity Score, and transfer time. } \\
\text { 'Baseline cortisol levels were available for } 22 \text { patients, but delta cortisol levels were available for } 21 \text { patients. }\end{array}$} \\
\hline
\end{tabular}

Based on published data at the time of planning this study, we determined the sample size from the hypothesis that the baseline $\mathrm{AI}$ rate would be $50 \%{ }^{37}$ and that etomidate would increase the rate of AI by $40 \% .{ }^{11}$ Fixing the alpha level (type I error) at 0.05 , our study had an $80 \%$ statistical power to detect a $40 \%$ difference in the cumulative incidence of AI with 40 participants. To detect a difference of $8 \%$ in the risk of $\mathrm{AI}$ in the same conditions, however, a sample size of 329 (in each group) would have been required, which would be extremely difficult to reach given the severity of the condition of these patients and the major ethical issues. This lack of power is reflected in the wide confidence intervals of the odds ratio for AI. Conscious of our limited statistical power, we also analyzed delta cortisol, the variable used to define AI. Analysis of this continuous variable permitted us to better document the effects of etomidate on adrenal reserve as measured by the ACTH stimulation test.

\section{Clinical significance of results and suggestions for future research}

The clinical significance of etomidate-induced AI remains uncertain in TBI victims. Although our results showed a trend for increased hydrocortisone use and mortality in the etomidate group, no conclusions can be made from our small observational study. Jabre and colleagues found that etomidate-induced AI did not impact mortality or morbidity compared to ketamine. ${ }^{19}$ Although these authors suggested that ketamine is a safe alternative to etomidate, their study was underpowered to examine mortality in TBI victims specifically (TBI victims were only a subgroup $[n=78]$ of the total study $[N=469]$; Frédéric Adnet, $M D$, personal communication, July 2009).

If etomidate's short-lived advantages in terms of hemodynamic stability and neuroprotective properties are accompanied by longer-acting negative side effects, ${ }^{18}$ alternative options, such as ketamine, could be considered. ${ }^{19}$ However, even though a systematic review suggested that ketamine is safe for TBI victims, ${ }^{39}$ a formal trial is needed to address this question. ${ }^{40}$ Thus, the ideal anesthetic agent for TBI victims remains to be identified. Hohl and colleagues suggested that "the burden of proof is to show that etomidate is as safe as other anesthetics and a noninferiority study would be needed to accomplish this." ${ }^{20}$ A large RCT would be ideal, but this is a daunting task in the unstable TBI victim in the ED.

A recent RCT exploring the effects of stress-dose hydrocortisone supplementation $(200 \mathrm{mg} / \mathrm{d})$ after etomidate use on the hemodynamic status of critically 


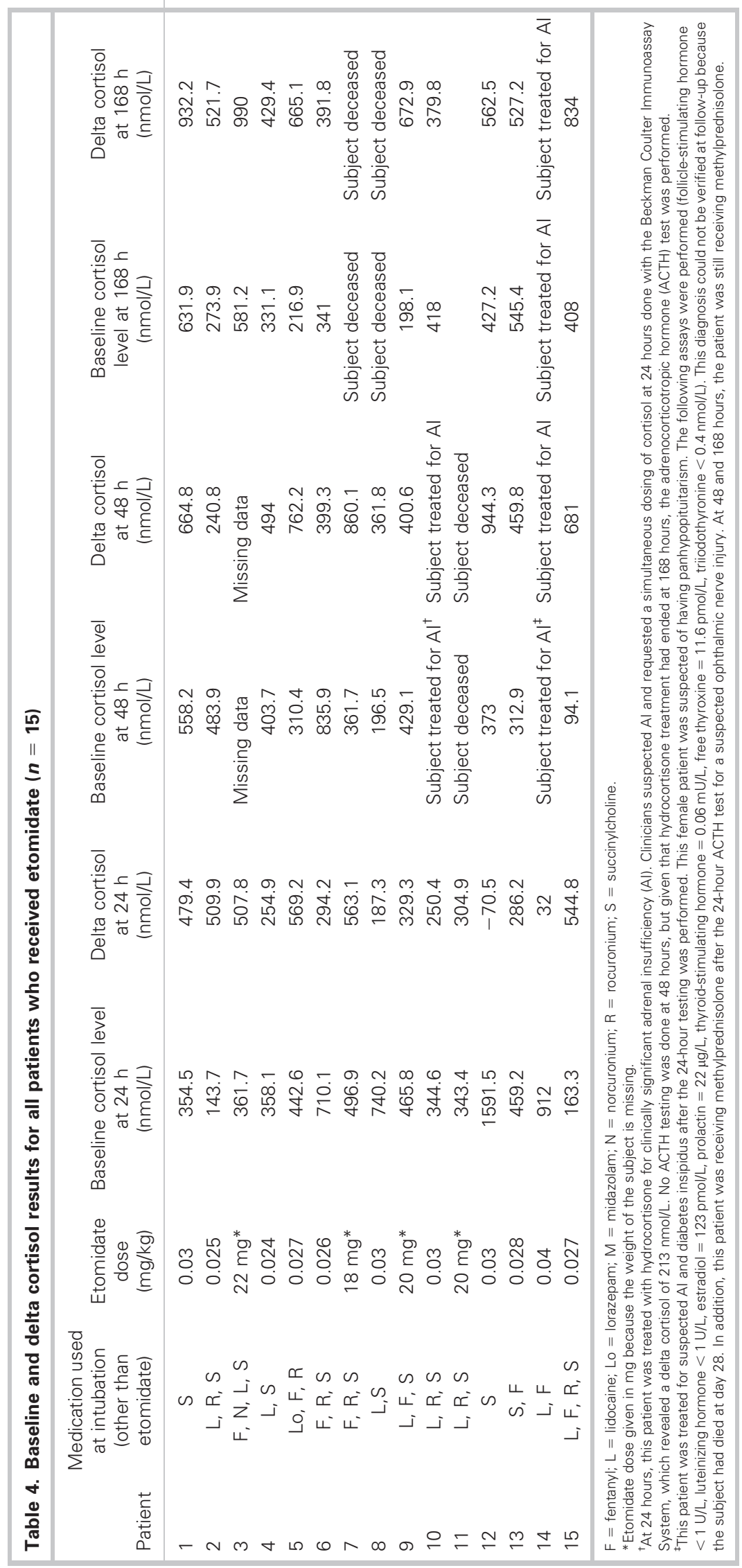




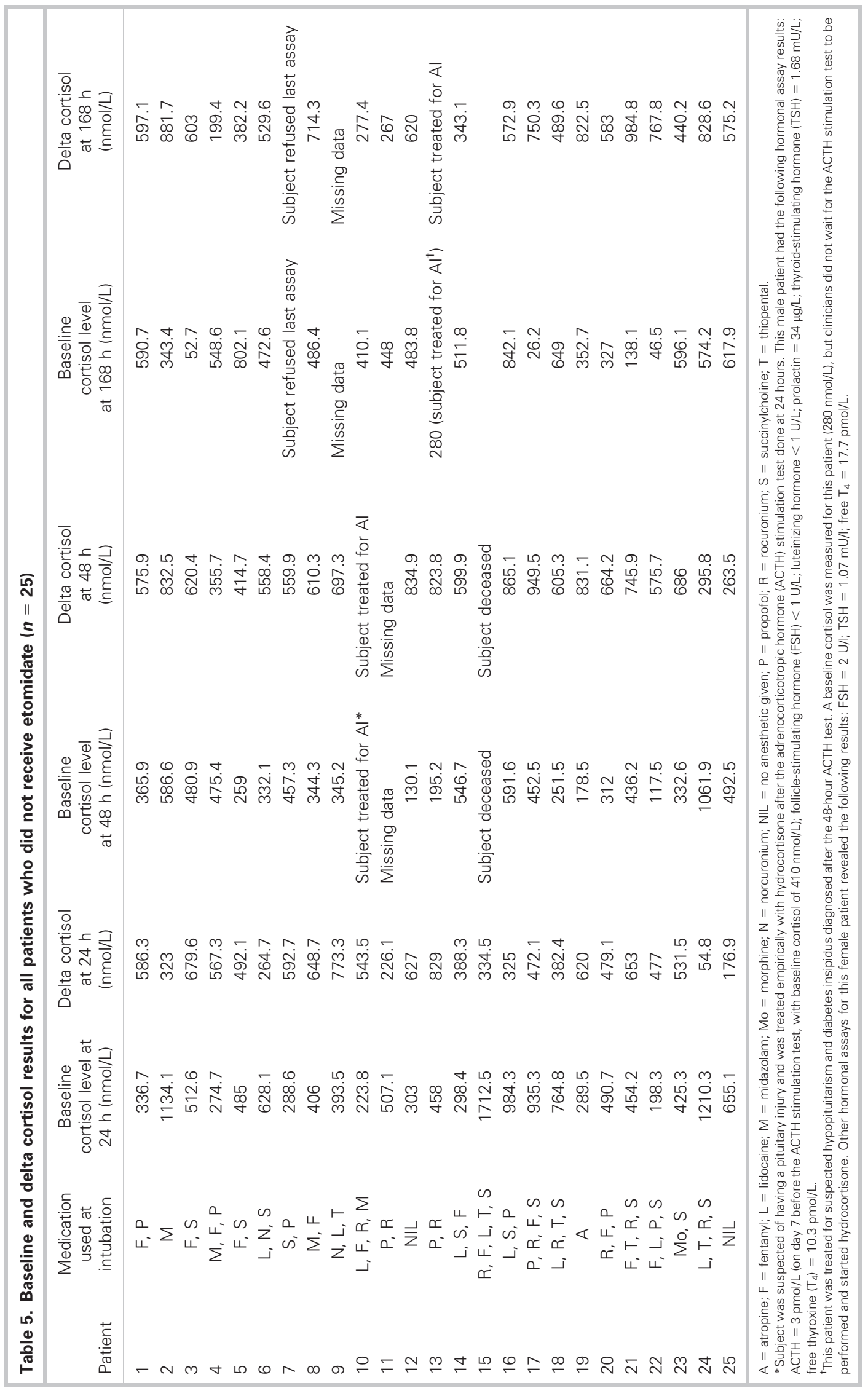


ill patients $(n=99)$ without septic shock, including isolated TBI $(n=18)$ and multiple trauma victims $(n=$ 42 ), found a reduction in the need for vasopressor support in patients receiving hydrocortisone. ${ }^{41}$ In this study, hydrocortisone was started only 6 hours after exposure to etomidate and continued for 48 hours. There was no benefit from hydrocortisone use with regard to ICU length of stay, duration of mechanical ventilation, or 28-day mortality. Another recent study with intubated trauma patients $(N=149)$, including patients exposed to etomidate $(n=94)$ and TBI victims $(n=84)$, found a decreased risk of hospitalacquired pneumonia for patients treated with stress doses of hydrocortisone compared to placebo. ${ }^{42}$ Thus, in light of these two recent studies and the results of our study, the next step would be to conduct a larger RCT with an adequate sample size to determine whether hydrocortisone supplementation given for 24 hours and started immediately after etomidate use in TBI victims has any potential clinical benefit.

\section{CONCLUSION}

The results of this study do not support the hypothesis that etomidate significantly increases the cumulative incidence of AI defined as a delta cortisol less than $248.4 \mathrm{nmol} / \mathrm{L}$ at 24, 48, or 168 hours. Exploratory post hoc analyses, however, show that etomidate negatively impacts the response to an ACTH test up to 24 hours among moderate to severe TBI victims. The clinical impacts of this finding remain to be determined.

Acknowledgement: We would like to thank the following people for their much appreciated help and support: Tim Allen, Pierre Archambault, Amina Belcaïd, Stéphanie Camden, Patricia Chabot, André Lavoie, Natalie Lesage, Linda Nadeau, Sandra Marshall, Diane Martineau, Guylaine Martineau, Lynne Moore, Rakesh Patel, Jennifer Petrela, André Pineau, Julien Poitras, and Geneviève Romanesky.

Competing interests: Funding was provided by the following: Association des médecins d'urgence du Québec, Programme national de recherche en traumatologie, Fondation des hôpitaux Enfant-Jésus et Saint-Sacrement, Université Laval/CHAU Hôtel-Dieu de Lévis Emergency Medicine Research Chair, Université Laval McLaughlin Fellowship Fund, and Fonds académique de recherche en soins intensifs de Québec.

\section{REFERENCES}

1. Bergen JM, Smith DC. A review of etomidate for rapid sequence intubation in the emergency department. 7 Emerg Med 1997;15:221-30, doi:10.1016/S0736-4679(96)00350-2.
2. Sagarin MJ, Barton ED, Chng YM, et al. Airway management by US and Canadian emergency medicine residents: a multicenter analysis of more than 6,000 endotracheal intubation attempts. Ann Emerg Med 2005;46:328-36, doi:10.1016/ j.annemergmed.2005.01.009.

3. Sakles JC, Laurin EG, Rantapaa AA, et al. Airway management in the emergency department: a one-year study of 610 tracheal intubations. Ann Emerg Med 1998;31:325-32, doi:10.1016/S0196-0644(98)70342-7.

4. Walls RM. Manual of emergency airway management. 2 nd ed. Philadelphia: Lippincott Williams \& Wilkins; 2004.

5. Marx JA, Hockberger RS, Walls RM, et al. Rosen's emergency medicine: concepts and clinical practice. 6th ed. Philadelphia: Mosby/Elsevier; 2006.

6. Allolio B, Dörr H, Stuttmann R, et al. Effect of a single bolus of etomidate upon eight major corticosteroid hormones and plasma ACTH. Clin Endocrinol (Oxf) 1985;22: 281-6, doi:10.1111/j.1365-2265.1985.tb03241.x.

7. Wagner RL, White PF. Etomidate inhibits adrenocortical function in surgical patients. Anesthesiology 1984;61:647-51, doi:10.1097/00000542-198412000-00003.

8. Fragen RJ, Shanks CA, Molteni A, et al. Effects of etomidate on hormonal responses to surgical stress. Anesthesiology 1984; 61:652-6, doi:10.1097/00000542-198412000-00004.

9. Duthie DJ, Fraser R, Nimmo WS. Effect of induction of anaesthesia with etomidate on corticosteroid synthesis in man. Br 7 Anaestb 1985;57:156-9, doi:10.1093/bja/57.2.156.

10. Crozier TA, Beck D, Schlaeger M, et al. Endocrinological changes following etomidate, midazolam, or methohexital for minor surgery. Anesthesiology 1987;66:628-35, doi:10.1097/ 00000542-198705000-00006.

11. Absalom A, Pledger D, Kong A. Adrenocortical function in critically ill patients $24 \mathrm{~h}$ after a single dose of etomidate. Anaesthesia 1999;54:861-7, doi:10.1046/j.1365-2044.1999.01003.x.

12. Schenarts CL, Burton JH, Riker RR. Adrenocortical dysfunction following etomidate induction in emergency department patients. Acad Emerg Med 2001;8:1-7, doi: 10.1111/j.1553-2712.2001.tb00537.x.

13. Vinclair M, Broux C, Faure P, et al. Duration of adrenal inhibition following a single dose of etomidate in critically ill patients. Intensive Care Med 2008;34:714-9, doi:10.1007/ s00134-007-0970-y.

14. Bloomfield R, Noble DW. Etomidate and fatal outcomeeven a single bolus dose may be detrimental for some patients. Br 7 Anaesth 2006;97:116-7, doi:10.1093/bja/ael124.

15. Annane D. ICU physicians should abandon the use of etomidate! Intensive Care Med 2005;31:325-6, doi:10.1007/ s00134-005-2560-1.

16. Morris C, McAllister C. Etomidate for emergency anaesthesia; mad, bad and dangerous to know? Anaesthesia 2005; 60:737-40, doi:10.1111/j.1365-2044.2005.04325.x.

17. Jackson WL Jr. Should we use etomidate as an induction agent for endotracheal intubation in patients with septic shock? A critical appraisal. Chest 2005;127:1031-8, doi:10.1378/chest.127.3.1031.

18. Hildreth AN, Mejia VA, Maxwell RA, et al. Adrenal suppression following a single dose of etomidate for rapid sequence induction: a prospective randomized study. 7 Trauma 2008;65:573-9, doi:10.1097/TA.0b013e31818255e8. 
19. Jabre P, Combes X, Lapostolle F, et al. Etomidate versus ketamine for rapid sequence intubation in acutely ill patients: a multicentre randomised controlled trial. Lancet 2009;374: 293-300, doi:10.1016/S0140-6736(09)60949-1.

20. Hohl CM, Kelly-Smith CH, Yeung TC, et al. The effect of a bolus dose of etomidate on cortisol levels, mortality, and health services utilization: a systematic review. Ann Emerg Med 2010;56:105-13 e5.

21. Bruns J Jr, Hauser WA. The epidemiology of traumatic brain injury: a review. Epilepsia 2003;44 Suppl 10:2-10, doi:10.1046/j.1528-1157.44.s10.3.x.

22. Fleminger $S$, Ponsford J. Long term outcome after traumatic brain injury. BM7 2005;331:1419-20, doi:10.1136/bmj.331.7530.1419.

23. Agha A, Phillips J, Thompson CJ. Hypopituitarism following traumatic brain injury (TBI). Br $\mathcal{F}$ Neurosurg 2007;21: 210-6, doi: 10.1080/02688690701253331.

24. Dimopoulou I, Tsagarakis S, Kouyialis AT, et al. Hypothalamic-pituitary-adrenal axis dysfunction in critically ill patients with traumatic brain injury: incidence, pathophysiology, and relationship to vasopressor dependence and peripheral interleukin-6 levels. Crit Care Med 2004;32:404-8, doi:10.1097/01.CCM.0000108885.37811.CA.

25. Tanriverdi F, Senyurek H, Unluhizarci K, et al. High risk of hypopituitarism after traumatic brain injury: a prospective investigation of anterior pituitary function in the acute phase and 12 months after trauma. 7 Clin Endocrinol Metab 2006;91: 2105-11, doi:10.1210/jc.2005-2476.

26. Cohan P, Wang C, McArthur DL, et al. Acute secondary adrenal insufficiency after traumatic brain injury: a prospective study. Crit Care Med 2005;33:2358-66, doi:10.1097/ 01.CCM.0000181735.51183.A7.

27. Cooper MS, Stewart PM. Corticosteroid insufficiency in acutely ill patients. $N$ Engl $f$ Med 2003;348:727-34, doi:10.1056/NEJMra020529.

28. Edwards P, Arango M, Balica L, et al. Final results of MRC CRASH, a randomised placebo-controlled trial of intravenous corticosteroid in adults with head injury-outcomes at 6 months. Lancet 2005;365:1957-9, doi:10.1016/S0140-6736(05)66552-X.

29. Roberts I, Yates D, Sandercock P, et al. Effect of intravenous corticosteroids on death within 14 days in 10008 adults with clinically significant head injury (MRC CRASH trial): randomised placebo-controlled trial. Lancet 2004;364:13218, doi:10.1016/S0140-6736(04)17188-2.

30. SanoFi Diagnostics Pasteur. Access immunoassay system manual of operation. SanoFi Pasteur Diagnostics; 1995.

31. Annane D, Sebille V, Charpentier C, et al. Effect of treatment with low doses of hydrocortisone and fludrocortisone on mortality in patients with septic shock. FAMA 2002; 288:862-71, doi:10.1001/jama.288.7.862.

32. Marik PE. Critical illness-related corticosteroid insufficiency. Chest 2009;135:181-93, doi:10.1378/chest.08-1149.

33. Annane D, Sebille V, Troche G, et al. A 3-level prognostic classification in septic shock based on cortisol levels and cortisol response to corticotropin. FAMA 2000;283:1038-45, doi:10.1001/jama.283.8.1038.

34. Weant KA, Sasaki-Adams D, Dziedzic K, et al. Acute relative adrenal insufficiency after aneurysmal subarachnoid hemorrhage. Neurosurgery 2008;63:645-50, doi:10.1227/ 01.NEU.0000325728.S0939.15.
35. Price KA, Allen U, Mandersloot G, et al. Effect of a single dose of etomidate on adrenal function in patients with trauma. Crit Care 2005;9 Suppl 1:P392, doi:10.1186/cc3455.

36. Bernard F, Outtrim J, Menon DK, et al. Incidence of adrenal insufficiency after severe traumatic brain injury varies according to definition used: clinical implications. $\mathrm{Br} \mathrm{J}$ Anaesth 2006;96:72-6, doi:10.1093/bja/aei277.

37. Hoen S, Asehnoune K, Brailly-Tabard S, et al. Cortisol response to corticotropin stimulation in trauma patients: influence of hemorrhagic shock. Anesthesiology 2002;97:80713, doi:10.1097/00000542-200210000-00010.

38. McCarney R, Warner J, Iliffe S, et al. The Hawthorne effect: a randomised, controlled trial. BMC Med Res Methodol 2007; 7:30, doi:10.1186/1471-2288-7-30.

39. Himmelseher S, Durieux ME. Revising a dogma: ketamine for patients with neurological injury? Anesth Analg 2005;101: 524-34, doi:10.1213/01.ANE.0000160585.43587.5B.

40. Sehdev RS, Symmons DA, Kindl K. Ketamine for rapid sequence induction in patients with head injury in the emergency department. Emerg Med Australas 2006;18:37-44, doi:10.1111/j.1742-6723.2006.00802.x.

41. Payen JF, Dupuis C, Trouve-Buisson $T$, et al. Corticosteroid after etomidate in critically ill patients: a randomized controlled trial. Crit Care Med 2012;40:29-35, doi:10.1097/CCM.0b013e31822d7938.

42. Roquilly A, Mahe PJ, Seguin P, et al. Hydrocortisone therapy for patients with multiple trauma: the randomized controlled HYPOLYTE study. 7AMA 2011;305:1201-9, doi:10.1001/jama.2011.360.

\section{APPENDIX 1: LIST OF ADDITIONAL CONFOUNDING VARIABLES CONSIDERED}

We considered respiratory rate, initial Glasgow Coma Scale (GCS) score, mean arterial pressure, presence of hemorrhagic shock, hypotensive episodes, fluid administration, blood transfusions, vasopressor use, transfer status, transfer time, underlying chronic illness (chronic hypertension, coronary heart disease, chronic respiratory illness, chronic liver disease), surgery in the first 24 hours of admission, mechanism of injury, presence of ethanol in the blood, illicit drug intoxication, New Injury Severity Score (NISS), baseline cortisol level, and albumin level. We hypothesized that these variables could increase the patient's risk of developing AI without receiving etomidate.

Confounding variables that changed the regression coefficient of exposure to etomidate by $10 \%$ or more were retained in the final models. Variables considered but not retained because of this criterion were initial GCS score, intoxication with an illicit drug, surgery in the first 24 hours of hospitalization, and the presence of hemorrhagic shock. 


\section{APPENDIX 2: SENSITIVITY ANALYSES}

To estimate the impact of referral or selection bias on test outcomes, we performed two sensitivity analyses. Given that our study did not include all eligible subjects for the adrenocorticotropic hormone (ACTH) stimulation test $(n=94)$, we first estimated the effect of including all subjects on the risk of developing adrenal insufficiency and on delta cortisol levels at 24 hours. Our second sensitivity analysis concerned referrals. In our jurisdiction, all intubated traumatic brain injury (TBI) patients are supposed to be automatically transferred to a level 1 trauma centre. It is possible, however, that some centres in our jurisdiction with neurosurgeons on staff transfer only the most severe TBI victims. Our second analysis therefore excluded all subjects referred from centres with a neurosurgeon on staff.

The sensitivity analyses conducted to estimate the impact of participation of eligible patients who did not actually participate $(n=54)$ did not change our conclusions. Imputation of the abnormal adrenal insufficiency (AI) rate (20\%) to etomidate-receiving nonparticipants and the normal AI rate (12\%) to non-etomidate-receiving nonparticipants produced an odds ratio of 2.11 (95\% CI $0.65-6.79)(p=0.21)$. This calculation assumed that 3 of
12 nonincluded etomidate recipients $(25 \%)$ would present with $\mathrm{AI}$ and that 5 of 42 nonincluded, nonetomidate recipients (12\%) would present with AI. Imputation of the normal AI rate $(12 \%)$ to both groups produced an odds ratio of 1.28 (CI $0.35-4.68)(p=0.71)$. The assumption here was that AI would be experienced by 1 of 12 etomidate recipients (8\%) and 5 of 42 recipients of another agent (12\%). Finally, imputation of the abnormal mean delta cortisol $(336.2 \mathrm{nmol} / \mathrm{L})$ to the 12 etomidate recipients and the normal mean delta cortisol $(481.9 \mathrm{nmol} / \mathrm{L})$ to the 42 nonetomidate recipients did not change our conclusions. Imputing the normal mean delta cortisol to all missed subjects, however, nullified the statistical significance of our findings (etomidate group $=408.7 \mathrm{mmol} / \mathrm{L}$ versus nonetomidate group $=478.8 \mathrm{mmol} / \mathrm{L} ; p=0.2$ ).

As regards the potential bias induced by the referral of patients $(n=3)$ from peripheral hospitals staffed by a neurosurgeon, sensitivity analyses for AI at 24 hours produced an adjusted odds ratio of 4.6 (CI $0.3-67.5$ ) for all patients versus an odds ratio of 3.5 (CI $0.1-$ 128.5) when the referred patients were excluded. Excluding these patients produced an adjusted delta cortisol at 24 hours of 331.6 (range 200.9-462.4) $\mathrm{mmol} / \mathrm{L}$ for the etomidate group versus 498.4 (range 413.6-583.3) $\mathrm{mmol} / \mathrm{L}$ for the nonetomidate group.

\begin{tabular}{|c|c|c|}
\hline & Study participants ( $n=40$ ) & $\begin{array}{l}\text { Eligible subjects who did not } \\
\text { participate in ACTH testing }(n=54)\end{array}$ \\
\hline Use of etomidate, $n(\%)$ & $15(38)$ & $12(22)$ \\
\hline Mean age, yr (SD) & $41(17)$ & $43(19)$ \\
\hline Male sex, $n(\%)$ & $29(73)$ & $37(69)$ \\
\hline Mean respiratory rate (SD) & $24(9)\{12\}^{*}$ & $23(9)\{9\}^{*}$ \\
\hline Mean arterial pressure, $\mathrm{mm} \mathrm{Hg}$ (SD) & $88(24)\{1\}^{*}$ & $100(20)\{4\}^{*}$ \\
\hline Mean Glasgow Coma Scale score (SD) & 7 (3) & $8(4)$ \\
\hline Subjects transferred, $n(\%)$ & $26(65)$ & $45(83)$ \\
\hline Surgery in first $24 \mathrm{~h}, n(\%)$ & $14(35)$ & $17(31)$ \\
\hline \multicolumn{3}{|l|}{ Mechanism of injury, $n(\%)$} \\
\hline Motor vehicle & $27(68)$ & $37(69)$ \\
\hline Fall & $11(28)$ & $15(28)$ \\
\hline Isolated blunt head injury & $2(5)$ & $1(2)$ \\
\hline Other & 0 & $1(2)$ \\
\hline Alcohol detected in blood test, $n(\%)$ & $9(23)$ & $11(20)$ \\
\hline Illicit drug detected in urine test, $n(\%)$ & $2(5)$ & $4(7)$ \\
\hline Mean ISS (SD) & $33(10)$ & $32(10)$ \\
\hline \multicolumn{3}{|l|}{ ISS ranges, $n(\%)$} \\
\hline $0-24$ & $7(18)$ & $10(19)$ \\
\hline $25-49$ & $30(75)$ & $43(80)$ \\
\hline $50-75$ & $3(8)$ & $1(2)$ \\
\hline Mean New ISS (SD) & $53(17)$ & $47(18)$ \\
\hline
\end{tabular}

